\title{
Alternative therapies for respiratory distress syndrome in preterm infants
}

\author{
This article was published in the following Dove Press journal: \\ Research and Reports in Neonatology \\ 22 November 20II \\ Number of times this article has been viewed
}

\author{
Ian P Sinha' \\ Sunil K Sinha ${ }^{2}$ \\ 'Division of Women's and Children's \\ Health, Institute of Translational \\ Medicine, University of Liverpool, \\ Liverpool, UK; ${ }^{2}$ Department of \\ Neonatology, University of Durham \\ and James Cook University Hospital, \\ Middlesbrough, UK
}

\begin{abstract}
There is growing interest in the use of noninvasive methods of providing respiratory support to preterm infants, especially those born at the limits of viability. This paper relates to the use of noninvasive forms of respiratory support, which could be used to treat preterm infants with respiratory distress syndrome (RDS). Evidence is reviewed from clinical trials that have evaluated the use of continuous positive airway pressure (CPAP), nasal intermittent positive airway pressure (NIPPV), and high flow nasal cannulae (HFNC).
\end{abstract}

Keywords: CPAP, NIPPV, RDS, preterm

\section{Background}

The aims of treatment of extremely preterm infants have shifted from simply trying to keep them alive, towards helping them survive without important long-term sequelae of prematurity, and with as normal quality of life as possible. This is particularly relevant to those born at the limits of viability, as many of these extremely low gestational age newborns (ELGANs), who would previously have died, are now surviving with chronic respiratory and neurodevelopmental problems. Methods used to provide lifesaving support to immature babies such as these should be based on sound physiological principles, and on evidence from randomized controlled trials (RCTs) that test their efficacy and safety in a scientifically rigorous manner.

Until recently, exogenous surfactant replacement therapy and mechanical ventilation (MV) has been the treatment of choice for preterm infants with respiratory distress syndrome (RDS). Due to the invasive nature of intubation and MV, however, neonatologists have held longstanding concerns over whether the benefits of this strategy outweigh its harms in all ELGANs. This has led to increasing interest in the use of alternative forms of respiratory support, which obviate the need for intubation and MV. These modalities can be broadly considered as either single-level pressure support or bi-level pressure support.

Examples of single-level pressure support include continuous positive airway pressure (CPAP) and high flow nasal cannulae (HFNC). In CPAP, single-measured pressure support is provided throughout the respiratory cycle. Nasal cannulae have also been suggested as a means of providing respiratory support. They have been widely used to deliver oxygen at low-flow rates. HFNC uses constant high gas flow and this can provide some degree of pressure support.

In bi-level pressure support, commonly known as Nasal Intermittent Positive Pressure Ventilation (NIPPV), two different pressure levels are delivered during the 
respiratory cycle. There are a large number of acronyms in the literature, reflecting the variety of devices used to provide this modality. ${ }^{1}$ In essence, these machines all provide a baseline continuous airway distending pressure, that is intermittently augmented by rises in pressure. These rises in pressure can be large, similar to those delivered via an endotracheal tube during invasive ventilation, or small (2-3 cm $\mathrm{H}_{2} \mathrm{O}$ ), and can be either synchronized or nonsynchronized with the infant's spontaneous breaths.

The primary focus of this paper is to summarize and interpret findings from RCTs that have evaluated CPAP delivered by nasal prongs or mask (nCPAP), HFNC, and NIPPV, as initial therapies for RDS in preterm infants. This paper does not discuss the roles of these modalities for treating apnea of prematurity, or to aid extubation.

In particular, this paper begins to address the following questions:

- What is the role of nCPAP as an alternative to mechanical ventilation?

- Should infants who are tried on CPAP receive surfactant?

- Can NIPPV be used as first-line respiratory therapy for neonatal RDS?

- Can HFNC be used as first-line respiratory support in ELGANS?

\section{nCPAP for RDS in preterm infants What is the role of nCPAP as an alternative to mechanical ventilation?}

Observational studies conducted before ${ }^{2}$ and after $^{3}$ the introduction of the routine use of surfactant in neonatal units suggest that infants with RDS who receive CPAP may be less likely to develop bronchopulmonary dysplasia (BPD) than those who were intubated and mechanically ventilated. Four RCTs have attempted to evaluate whether CPAP is a safe and effective alternative to MV. The characteristics of these studies are shown in Table 1 and are described below.

The CPAP or intubation at birth (COIN) trial ${ }^{4}$ was an international, multicenter, randomized, open-label, controlled study in which 610 infants, of 25-29 weeks gestational age (GA) at birth, were randomized, after clinical assessment over the first 5 minutes of life, to one of two groups. In one group, infants were treated with nCPAP, and in the other they were intubated, administered surfactant, and placed on MV. With regard to the primary outcome, of death or BPD at 36 weeks gestational age, the authors found no differences between those infants randomized to nCPAP or MV (odds ratio [OR] favoring CPAP: 0.80; 95\% confidence interval [CI]: 0.58-1.12). There was, however, reduced incidence of the composite secondary outcome of death, as well as need for supplementary oxygen or respiratory support at 28 days in the nCPAP group, regardless of gestation (OR: 0.63 , 95\% CI: 0.41-0.83). Statistically significant benefits for this outcome were also observed when 405/610 infants of 27 or 28 weeks GA were analyzed as a subgroup (OR: 0.58, 95\% CI: 0.39-0.86), but not in the group of 205/610 infants of 25 or 26 weeks GA (OR: 0.49, CI: 0.17-1.39). There was no difference between the groups for other secondary outcomes reflecting common sequelae of prematurity, but there was an increased incidence of pneumothorax in the nCPAP group (9\% vs 3\%, $P<0.001)$. When considering the external generalizability of these results, it is important to remember that they are not applicable to all preterm infants, but rather those who were stable enough to not require respiratory support in the first 5 minutes of life.

The Early CPAP vs Surfactant in Extremely Preterm Infants (SUPPORT) trial ${ }^{5}$ was also a multicenter, randomized, openlabel, controlled study, in which 1318 infants of 24-28 weeks GA were randomized, before birth, to receive either nCPAP, or

Table I Randomized controlled trials comparing CPAP with mechanical ventilation in preterm infants

\begin{tabular}{|c|c|c|c|c|}
\hline Trial & $\begin{array}{l}\text { Gestational age of } \\
\text { included infants (weeks) }\end{array}$ & $\mathbf{N}$ & Comparison & Main conclusion \\
\hline $\mathrm{COIN}^{4}$ & $\begin{array}{l}\text { 25-29 (excluding infants who required } \\
\text { intubation within the first } 5 \text { minutes) }\end{array}$ & 610 & nCPAP vs surfactant and $M V$ & $\begin{array}{l}\text { No difference with regards to primary outcome } \\
\text { of death or BPD at } 36 \text { weeks gestational age }\end{array}$ \\
\hline SUPPORT $^{5}$ & $24-28$ & 1316 & nCPAP vs surfactant and MV & $\begin{array}{l}\text { No difference with regards to primary outcome } \\
\text { of death or BPD at } 36 \text { weeks gestational age }\end{array}$ \\
\hline $\begin{array}{l}\text { Vermont } \\
\text { Oxford }\end{array}$ & $26-29$ & 648 & $\begin{array}{l}\text { Surfactant and MV vs surfactant } \\
\text { and rapid extubation vs } \\
\text { early CPAP with selective } \\
\text { intubation and surfactant, } \\
\text { if required }\end{array}$ & $\begin{array}{l}\text { No difference with regards to primary outcome } \\
\text { of death or BPD at } 36 \text { weeks gestational age }\end{array}$ \\
\hline IFDAS $^{7}$ & $27-29$ & 237 & nCPAP or MV & $\begin{array}{l}\text { No difference with regards to primary outcome } \\
\text { of death or BPD at } 36 \text { weeks gestational age }\end{array}$ \\
\hline
\end{tabular}

Abbreviations: COIN, CPAP or intubation at birth; SUPPORT, Early CPAP vs surfactant in extremely preterm infants; IFDAS, Early nasal CPAP with prophylactic surfactant for neonates at risk of RDS; BPD, bronchopulmonary dysplasia; MV, mechanical ventilation; $\mathrm{nCPAP}$, nasal continuous positive airway pressure. 
intubation, surfactant, and MV. There was no difference between the groups with regard to the composite outcome of death or BPD at 36 weeks GA (relative risk [RR] with CPAP: 0.95, 95\% CI: 0.85-1.05), or with regard to secondary outcomes reflecting common sequelae of prematurity. However, there were significant differences in secondary outcomes reflecting health care utilization, as there was a reduction in the number of days of mechanical ventilation required by babies randomized to the nCPAP group (difference in means: 3.0 days, 95\% CI: 0.3-5.6). These results, however, are difficult to interpret because of discrepancies in criteria for extubation between infants randomized to nCPAP, who then required intubation, and those who were randomized to surfactant and $\mathrm{MV}$, as these differences would lead to earlier fulfillment of extubation criteria in those infants in whom the initial use of nCPAP had 'failed'.

The Vermont Oxford Network Trial ${ }^{6}$ compared the following three treatment strategies for infants with RDS, of 26-29 weeks GA at birth: (1) intubation, surfactant, and MV; (2) intubation, surfactant, and rapid extubation; and (3) early CPAP with selective intubation and surfactant, if required. There was no difference between any arms with regard to the primary outcome, of death or BPD at 36 weeks gestational age, but this trial was terminated early, as only 648 out of the 876 required infants could be recruited. In the Early nasal CPAP with prophylactic surfactant for neonates at risk of RDS (IFDAS) trial, ${ }^{7} 237$ babies of 27-29 weeks gestation were randomized to receive nCPAP or MV. Again, there were no differences in the rates of BPD at 36 weeks or other complications of prematurity between the study groups.

The results of these four studies suggest that the routine use of CPAP, when compared with MV, does not prevent death or BPD at 36 weeks. Two other important inferences can be made from the results, however.

First, not all ELGANs with RDS will require MV as first-line respiratory therapy. Of all the babies randomized to CPAP, $46 \%$ in the COIN trial, and $83 \%$ in the SUPPORT trial subsequently required intubation. The results of the COIN trial suggest that clinicians may be able to decide, in the delivery room, which babies will only require CPAP and which will require MV.

Second, CPAP can cause complications. Although it is considered a 'gentler' treatment than MV, there was a $9 \%$ incidence of pneumothorax amongst infants randomized to CPAP in the COIN trial. A recent prospective observational study has shown that nasal trauma is another common complication of nCPAP, and this is especially true in preterm neonates, but they also concluded that long-term cosmetic sequelae are rare. ${ }^{8}$

\section{Which CPAP device should be used?}

Various devices are available for the delivery of nasal CPAP. These can be broadly considered, on the basis of the characteristics of the gas flow they generate, as either variable flow (such as the infant flow driver [IFD] [Electro Medical Equipment, Sussex, UK]) or continuous flow devices (such as Bubble CPAP [Fisher and Paykel HealthCare, Auckland, New Zealand]). IFD is purported to have the physiological advantages of providing more stable pressure delivery, improving functional residual capacity, and reducing thoracoabdominal asynchrony. ${ }^{9}$ The physiological rationale behind bubble CPAP is that the bubbles which are used to generate pressure also create chest vibrations, and that this mechanism improves gas exchange. ${ }^{10}$

No published trials have compared the effectiveness of bubble CPAP with that of IFD CPAP when used as the initial mode of respiratory support in preterm infants with RDS. Only one RCT has compared the two modalities, when used in 140 preterm infants (24-29 weeks gestational age, with birth weight of 600-1500 g), who were being weaned from MV. ${ }^{11}$ The overall incidence of extubation failure for the entire study cohort was $22.1 \%$. The proportion of infants who failed extubation was $16.9 \%$ in the bubble CPAP group and $27.5 \%$ in the IFD CPAP group $(P=0.130)$. However, in an analysis of a subgroup of those infants who were ventilated for less than 14 days $(\mathrm{N}=127)$, the extubation failure rate was significantly lower in those infants randomized to bubble CPAP (14.1\%) than those who received IFD CPAP $(28.6 \%)(P=0.046)$. The main difficulties in interpreting the results of this trial are that it was conducted at a single center and does not assess longterm outcomes. Large scale, multicenter RCTs comparing the effectiveness of these devices will be required to detect differences between them.

\section{The use of surfactant for preterm babies receiving CPAP}

Seven RCTs have examined whether preterm infants who are treated with CPAP should receive "prophylactic" or "early" surfactant, even if they are clinically stable, or whether it should instead be used as "rescue" therapy in those infants in whom there is a persistent oxygen requirement, established respiratory distress, or respiratory failure. The strategy for giving early surfactant is often known as the INSURE technique (INtubation, SURfactant, Extubation).

Six of these trials ${ }^{12-17}$ have been included in a Cochrane Review ${ }^{18}$ and one trial has been published since this review was conducted. ${ }^{19}$ These trials are summarized in Table 2. 
Table 2 Randomized controlled trials comparing the use of "early" surfactant vs "rescue"” surfactant in infants receiving CPAP

\begin{tabular}{|c|c|c|c|}
\hline Trial & Population & $\mathbf{N}$ & $\begin{array}{l}\text { Main conclusion (regarding 'treatment failure', } \\
\text { defined as the need for MV) }\end{array}$ \\
\hline Verder et al ${ }^{12, *}$ & 25-35 weeks GA & 73 & Early surfactant reduced the need for MV \\
\hline Haberman et $\mathrm{al}^{13, * *}$ & $1250-2000 \mathrm{~g}$, and $<12$ hours old & 61 & No difference between early and rescue surfactant \\
\hline Soll et $\mathrm{al}^{15}$ & $\mathrm{I} 00 \mathrm{I}-2500 \mathrm{~g}$, and $2-24$ hours old & 270 & No difference between early and rescue surfactant \\
\hline Escobedo et al $^{14}$ & $\begin{array}{l}>1250 \text { grams, }<36 \text { weeks GA, } \\
\text { and } 4-24 \text { hours old }\end{array}$ & 132 & Early surfactant reduced the need for MV \\
\hline Dani et al ${ }^{16, *}$ & $<30$ weeks $\mathrm{GA}$, and $<6$ hours old & 27 & $\begin{array}{l}\text { Early surfactant did not reduce the need for MV } \\
\text { (though trial stopped early because at interim } \\
\text { analysis, there was a difference between the groups } \\
\text { in terms of need for MV at } 7 \text { days) }\end{array}$ \\
\hline Reininger et $\mathrm{al}^{17}$ & 25-36 weeks GA, and $<24$ hours old & 60 & Early surfactant reduced the need for $M V$ \\
\hline Sandri et al ${ }^{19}$ & $25-28$ weeks $G A$, and $<30$ minutes old & 208 & No difference between early and rescue surfactant \\
\hline
\end{tabular}

Meta-analysis of studies included in the Cochrane review shows that, when compared with its use as rescue therapy, the early use of surfactant was associated with reduced need for mechanical ventilation (typical RR: 0.67, 95\% CI: $0.57-0.79$ ), risk of air leak syndromes (typical RR: 0.52, 95\% CI: 0.28-0.96), and development of BPD (typical RR: $0.51,95 \%$ CI: $0.26-0.99)$. In contrast, the other trial, published since the Cochrane review, ${ }^{19}$ found no difference in outcome between the use of "early" and "rescue" surfactant (need for MV in the first 5 days of life $31.4 \%$ in early group vs $33 \%$ in rescue group (RR: $0.95,95 \%$ CI: $0.64-0.41 ; P=0.80)$.

In another RCT, which was excluded from the Cochrane review, because intubated infants received a planned period of $M V,{ }^{20}$ the use of early surfactant was compared with rescue surfactant in infants born younger than 30 weeks GA. It was stopped early, after interim analysis of 60 patients (projected sample size 200), as there was significant benefit for babies treated with early surfactant in terms of the mean ratio of arterial to alveolar oxygen tension 6 hours after randomization ( 0.48 in the early-surfactant-treated babies vs 0.36 in the "rescue" group; $P=0.02$ ). Also, the need for subsequent mechanical ventilation or death within the first 7 days was reduced ( $21 \%$ of the early-surfactant-treated babies vs $63 \%$ of the "rescue" group; $P=0.0013$ ).

The results of these RCTs suggest that some babies will benefit from early surfactant therapy and that this approach is generally safer than using this drug as rescue therapy. However, a "blanket" approach to giving surfactant to all preterm infants requiring CPAP may expose some of these babies to the risks of intubation and surfactant delivery when they may not need it. One area of current experimental interest is in the use of nebulized surfactant, which has been evaluated in neonates in small, early-phase clinical trials. ${ }^{21-23}$ Although the technique appears to be well tolerated, later-phase trials must be conducted to compare the benefits and harms of this technique with those of administration of intra-tracheal surfactant. ${ }^{24}$

\section{Key points}

Not all preterm infants with RDS will require MV. There is no evidence, however, supporting the use of nCPAP as firstline respiratory support in all of these patients. The use of CPAP is more likely to be successful in infants who receive early, prophylactic surfactant when compared with those infants who receive it as a rescue therapy. Medical caregivers must remember that fragile preterm infants who require any form of respiratory support, including nCPAP, are prone to complications of treatment.

\section{Can HFNC be used as a primary mode of respiratory support in ELGANS, rather than nCPAP?}

Nasal cannulae are commonly used to provide oxygen at low flow rates to neonates but it has been suggested that using higher rates of oxygen flow $(>1 \mathrm{~L} /$ minute, and commonly 2-8 L/minute), through larger diameter cannulae, could also deliver positive distending pressure. It has been suggested that this may be safer than nCPAP, especially in terms of nasal trauma. ${ }^{25}$ However, it is important to remember that the pressure support provided by HFNC is unregulated as the user cannot control or monitor it. The proposed mechanisms by which delivery of humidified oxygen using HFNC may improve respiratory efficiency are the flushing of dead space in the nasopharyngeal cavity, reduction in inspiratory flow 
resistance, which leads to reduced work of breathing, improvement in pulmonary mechanics, and the delivery of positive distending pressure.

Most RCTs of HFNC oxygen have focused on its use as a tool to aid extubation. ${ }^{26}$ Only one small trial has examined whether HFNC oxygen can be used as the initial mode of respiratory support in preterm infants. ${ }^{27}$ In this study, 67 infants with RDS, of 27-34 weeks GA at birth, were randomized to receive either HFNC oxygen or nCPAP. There was no difference in the rate of respiratory failure requiring intubation between the two groups (4/33 in the HFNC group vs $4 / 34$ in the CPAP group). This trial, which has only been published in abstract format, was stopped early because the machine used to deliver HFNC oxygen was recalled by the manufacturer.

Although detailed discussion about the roles of various modalities of respiratory support as tools to aid extubation is outside the scope of this review, it is notable that in one small trial $^{28}$ the rates of re-intubation were higher in those infants extubated to HNFC than in those randomized to nCPAP. One reason for the lack of evidence supporting the routine use of HFNC is the fact that, at present, the most effective and safe flow rate is not known. Future research should focus on addressing this question.

There have been concerns about the safety of HFNC (which has been associated with mucosal irritation, nasal obstruction, epistaxis, increased risk of nosocomial infection, and contamination of delivery devices with Gram-negative organisms) although adverse effects could not be rigorously evaluated in a recent Cochrane review. ${ }^{26}$

\section{Key points}

HFNC should not be used as first-line respiratory support for preterm infants with RDS. Users must remember that they have no control over the level of pressure support provided when utilizing HFNC and no means of monitoring it.

\section{Can NIPPV be used as first-line respiratory therapy for neonatal RDS?}

Recent RCTs have attempted to evaluate whether NIPPV can be used as the initial treatment for neonatal RDS. These are summarized in Table 3.

In one of these studies, 41 infants of less than 32 weeks GA at birth, who had already received surfactant, were randomized to one of two groups: (1) rapid extubation to NIPPV; or (2) ongoing $\mathrm{MV}^{29}$ The incidence of the composite primary outcome (BPD or death) was reduced from $52 \%$ in the MV group to $20 \%$ in the NIPPV group $(P=0.03)$. Recruitment of infants into this study, however, was terminated before the calculated sample size $(\mathrm{N}=50)$ had been accrued.

In the other trials NIPPV was compared with nCPAP, primarily to evaluate which mode of respiratory support was associated with lower risk of the need for intubation. In each of these studies, infants judged in the delivery room to need respiratory support (though not necessarily MV) were randomized to NIPPV or nCPAP. The primary outcome was the need for intubation.

The most recent of these trials ${ }^{30}$ included 200 infants of 26-34 weeks GA at birth and found no difference in the rates of intubation ( $25 \%$ in NIPPV group vs $34 \%$ in NCPAP group; RR: $0.71,95 \%$ CI: $0.48-1.14)$ or in rates of BPD $(26.5 \%$ in NIPPV group vs $25 \%$ in NCPAP group; RR: $1.06,95 \%$ CI: 0.62-1.78). In the other trials, however, NIPPV was shown to have some beneficial effects when compared with NCPAP as the primary mode of respiratory support.

In one of the these trials, ${ }^{31}$ which included 84 infants of 24-34 weeks GA, the proportion of infants requiring

Table 3 Randomized controlled trials evaluating NIPPV as treatment for RDS in preterm infants

\begin{tabular}{|c|c|c|c|}
\hline Trial & Population & $\mathbf{N}$ & $\begin{array}{l}\text { Main conclusions with regard to need for } M V \text {, } \\
\text { and rates of BPD }\end{array}$ \\
\hline Bhandari et $\mathrm{al}^{29, *}$ & $<32$ weeks GA & 41 & $\begin{array}{l}\text { NIPPV reduced rates of BPD or death } \\
\text { (when compared with ongoing } \mathrm{MV} \text { ) }\end{array}$ \\
\hline Kugelman et $\mathrm{al}^{31}$ & $<35$ weeks GA & 84 & NIPPV reduced need for $M V$, and reduced rates of BPD \\
\hline Bisceglia et $\mathrm{al}^{32}$ & Preterm infants & 88 & Reduced need for MV in NIPPV group \\
\hline Ramanathan et $\mathrm{al}^{34}$ & Awaiting full study report & 110 & NIPPV reduced need for $M V$, and reduced rates of BPD \\
\hline Sai Sunil Kishore et al $^{33}$ & 28-34 weeks & 76 & $\begin{array}{l}\text { NIPPV reduced need for } M V \text {, but was not associated } \\
\text { with reduced rates of BPD }\end{array}$ \\
\hline Meneses et $\mathrm{al}^{30}$ & $26-34$ weeks & 200 & $\begin{array}{l}\text { No difference between } \mathrm{nCPAP} \text { and NIPPV group with } \\
\text { regard to need for } \mathrm{MV} \text {, or rates of BPD }\end{array}$ \\
\hline
\end{tabular}

Note: *Trial terminated early.

Abbreviations: GA, gestational age; MV, mechanical ventilation; RDS, respiratory distress syndrome; BPD, bronchopulmonary dysplasia; NIPPV, nasal intermittent positive pressure ventilation; nCPAP, nasal continuous positive airway pressure. 
intubation was significantly lower in those who received NIPPV, as compared with those randomized to nCPAP $(25 \%$ vs $49 \%, P<0.05)$. Furthermore, in this trial, rates of BPD were reduced in the group of infants treated with NIPPV, both in the total cohort $(2 \%$ vs $17 \%, P<0.05)$ and in a subgroup analysis of infants weighing $<1500 \mathrm{~g}(5 \%$ vs $33 \%$, $P<0.05)$. In another, of 88 infants randomized either to NIPPV or nCPAP, rates of intubation at 4 hours were also reduced in those infants requiring NIPPV. ${ }^{32}$ This trial also showed that NIPPV conferred physiological advantages over nCPAP. In a trial of 76 preterm infants (28-34 weeks GA), rates of "treatment failure" (the primary outcome) were lower in the NIPPV group (13.5\% in NIPPV group vs $35.9 \%$ in CPAP group; RR: 0.38, 95\% CI: 0.15-0.89; $P=0.024) .{ }^{33}$ With regards to secondary outcomes, infants randomized to NIPPV had reduced need for intubation and mechanical ventilation by 7 days $(18.9 \%$ in NIPPV group vs $41 \%$ in CPAP group; $P=0.036$ ), but not a reduced risk of BPD (2.7\% in NIPPV group vs 7.7 in CPAP group; $P=0.61$ ). A further trial comparing early use of NIPPV with NCPAP, in preterm infants who received surfactant, has been presented in abstract form and the full study report is anticipated. ${ }^{34}$ The results of this study also suggest that NIPPV is associated with reduced need for MV and reduced risk of $\mathrm{BPD}$. One relevant $\mathrm{RCT}^{35}$ is still recruiting patients. A Cochrane review of trials of NIPPV for preterm infants with RDS is awaited. ${ }^{36}$

\section{Key points}

There is accumulating evidence that NIPPV can be a more effective treatment than nCPAP for preterm infants with RDS. It can prevent the need for $\mathrm{MV}$, and may reduce the risk of BPD, when compared with nCPAP.

\section{Difficulties in interpreting clinical trials of respiratory therapies for preterm babies}

There are many difficulties that researchers face when designing and conducting clinical trials of respiratory therapies for preterm infants, some of which are outlined below:

1. Masking interventions: it is unfeasible, in many situations, to mask the group to which infants are randomized.

Although this will not impact directly on the measurement of "hard" objective outcomes such as mortality, openlabel trials such as these will be prone to performance bias. It is possible, however, to ensure that people involved in recording and analyzing data are blinded so they do not know which infants received which intervention.

2. Recruitment of patients: several of the trials mentioned above were terminated early because of failure to accrue an appropriate number of patients. This is likely due to high levels of anxiety amongst parents at such a stressful time and also amongst medical caregivers who may feel uncomfortable about approaching these parents with the request of participating in a clinical trial.

3. Determining which outcomes are most important: it can be difficult to know which outcomes are most relevant in clinical trials of respiratory therapies for children. For example, parents may be more interested in long-term respiratory complications in infancy and later childhood, or in long-term measures of quality of life, but these may be impractical for researchers, who may feel that short-term measures of morbidity are more important or feasible. For expensive interventions (such as ventilators or CPAP devices) health care commissioners, insurers, or payers may be more interested in economic outcomes reflecting health resource utilization, such as number of days requiring intensive care admission or duration of ventilation. There are also many ways in which these outcomes can be measured and many time-points at which data could be collected..$^{37}$ One solution to these problems could be to develop core outcome sets, ${ }^{38,39}$ that are a minimum set of outcomes that should be measured and reported, in all clinical trials of respiratory therapies for preterm infants.

4. Differing populations and centers with varying levels of expertise: one factor which is likely to impact on the effectiveness of modalities for respiratory support is the level to which centers are comfortable with using them. This includes expertise of medical and nursing staff. This is relevant when interpreting clinical trials because the reader must assess the external generalizability of results with regard to whether they are applicable in their own institution - for example, what may be highly effective in a department which has used a mode of respiratory support for years may not be so effective in another, and what is useful in high-income countries may be difficult to use in low-income countries. Similarly, differing practices with regard to extubation and intubation criteria between centers, that can also be seen in the nonuniformity of such definitions across clinical trials, must be taken into account when people read reports of these studies and consider whether a particular mode of respiratory support should be used in their institution. 


\section{Conclusion and unanswered questions}

1. In some preterm infants, CPAP can be used as the primary mode of respiratory support instead of MV.

2. For some of these infants CPAP is more likely to be effective if surfactant is given as "early" treatment, rather than as rescue therapy for RDS. If it were possible to identify these infants, targeted administration of surfactant prophylactically, rather than as rescue therapy, may lead to better outcomes. Until clinical prediction tools have been developed and validated, it would be prudent to adhere to recent guidelines that recommend prophylactic surfactant replacement should be "considered for extremely preterm infants at high risk of respiratory distress syndrome, especially infants who have not been exposed to antenatal steroids." ${ }^{40}$

3. NIPPV may prove to be a good alternative to nCPAP, as the results of some RCTs suggest it may be more effective at obviating the need for intubation and MV and that it may reduce the risk of BPD.

4. There is currently no evidence that HFNC oxygen should be used instead of nCPAP as the initial modality of respiratory support for ELGANS.

Future research should address the following:

1. There is a need to develop and validate tools to help predict in which babies nCPAP is likely to be effective when used as the first therapy for RDS and in which babies it is likely to fail. Some work has been conducted to attempt to address this question although reliable indicators of those babies who are likely to develop respiratory failure, even when treated with nCPAP, have not as yet been identified. ${ }^{41,42}$

2. There is a need to determine the optimal manner in which to use CPAP, in order to avoid the need for intubation and to prevent the occurrence of complications.

3. The long-term benefits and harms of CPAP and NIPPV, as compared with MV, must be evaluated.

4. Synchronized and nonsynchronized methods of providing NIPPV should be directly compared in terms of the benefits they confer on important clinical outcomes.

5. New forms of respiratory support which are designed to improve synchronization of breaths between the patient and the ventilator are being developed for use in other settings and it will be important to consider and evaluate their use in preterm infants. Proportional assist ventilation and neurally adjusted ventilatory assist (NAVA) aim to improve patient/ventilator interaction by matching the assisted breaths with the neural output of the respiratory centers, either by continuously adjusting support in line with predicted inspiratory effort (proportional assist ventilation) or with the electrical activity of the diaphragm (NAVA). ${ }^{43}$

Until such time as these questions are answered, it would be prudent to suggest that treatment options for ELGANS are considered on an individual basis - what is ideal for one infant may not be for another. At the heart of making evidence-based decisions about treatment is that the results of the best quality evidence must be placed in context along with clinical expertise and judgment about individual patients. This decision-making process will be made much easier if well-designed, rigorously conducted clinical research is conducted to address the questions outlined above.

\section{Acknowledgment}

Ian Sinha is supported by a National Institute of Health Research Clinical Lecturer Award.

\section{Disclosure}

The authors report no conflicts of interest in this work.

\section{References}

1. Davis PG, Morley CJ, Owen LS. Non-invasive respiratory support of preterm neonates with respiratory distress: continuous positive airway pressure and nasal intermittent positive pressure ventilation. Semin Fetal Neonatal Med. 2009;14(1):14-20.

2. Avery ME, Tooley WH, Keller JB, et al. Is chronic lung disease in low birthweight infants preventable - a survey of 8 centers. Pediatrics. 1987; 79(1):26-30.

3. Van Marter LJ, Allred DN, Leviton A, Pagano M, Parad R, Moore M. Antenatal glucocorticoid treatment does not reduce chronic lung disease among surviving preterm infants. J Pediatr. 2001;138(2):198-204.

4. Morley CJ, Davis PG, Doyle LW, Brion LP, Hascoet JM, Carlin JB. Nasal CPAP or intubation at birth for very preterm infants. $N$ Engl J Med. 2008;358(7):700-708.

5. Finer NN, Carlo WA, Walsh MC, et al. Early CPAP versus surfactant in extremely preterm infants. N Engl J Med. 2010;362(21):1970-1979.

6. Dunn MS, Kaempf J, de Klerk A et al. Randomized trial comparing 3 approaches to the initial respiratory management of preterm neonates. Paediatrics; 2011 Oct 24. Epub ahead of print.

7. Thomson MA. Early nasal continuous positive airways pressure (nCPAP) with prophylactic surfactant for neonates at risk of RDS. The IFDAS multi-centre randomised trial. Pediatr Res. 2002;51:379A.

8. Fischer C, Bertelle V, Hohlfeld J, Forcada-Guex M, StadelmannDiaw C, Tolsa JF. Nasal trauma due to continuous positive airway pressure in neonates. Arch Dis Child Fetal Neonatal Ed. 2010;95(6): F447-F451.

9. Courtney SE, Barrington KJ. Continuous positive airway pressure and noninvasive ventilation. Clin Perinatol. 2007;34(1):73-92.

10. Pillow JJ, Hillman N, Moss TJM, et al. Bubble continuous positive airway pressure enhances lung volume and gas exchange in preterm lambs. Am J Respir Crit Care Med. 2007;176(1):63-69.

11. Gupta S, Sinha SK, Tin W, Donn SM. A randomized controlled trial of post-extubation bubble continuous positive airway pressure versus Infant Flow Driver continuous positive airway pressure in preterm infants with respiratory distress syndrome. J Pediatr. 2009;154(5):645-650. 
12. Verder H, Robertson B, Greisen G, et al. Surfactant therapy and nasal continuous positive airway pressure for newborns with respiratory distress syndrome. N Engl J Med. 1994;331(16):1051-1055.

13. Haberman B, Shankaran S, Stevenson DK, et al. Does surfactant (S) and immediate extubation to nasal continuous positive airway pressure (CPAP) reduce use of mechanical ventilation? Pediatric Research. 2002;51:349A.

14. Escobedo MB, Gunkel JH, Kennedy KA, et al. Early surfactant for neonates with mild to moderate respiratory distress syndrome: A multicenter, randomized trial. J Pediatr. 2004;144(6):804-808.

15. Soll, Conner, Howard, et al. Early surfactant replacement in spontaneously breathing premature infants with RDS. Pediatr Res. 2003;4213C.

16. Dani C, Bertini G, Pezzati M, Cecchi A, Caviglioli C, Rubaltelli FF. Early extubation and nasal continuous positive airway pressure after surfactant treatment for respiratory distress syndrome among preterm infants < 30 weeks' gestation. Pediatrics. 2004;113(6): E560-E563.

17. Reininger A, Khalak R, Kendig, et al. Surfactant administration by transient intubation in infants 29 to 35 weeks' gestation with respiratory distress syndrome decreases the likelihood of later mechanical ventilation: a randomized controlled trial. J Perinatol. 2005;25(11): 703-708.

18. Stevens TP, Harrington EW, Blennow M, Soll RF. Early surfactant administration with brief ventilation versus. selective surfactant and continued mechanical ventilation for preterm infants with or at risk for respiratory distress syndrome. Cochrane Database Syst Rev. 2007; 4:CD003063.

19. Sandri F, Plavka R, Ancora G, et al. Prophylactic or early selective surfactant combined with nCPAP in very preterm infants. Pediatrics. 2010;125(6):E1402-E1409.

20. Verder H, Albertsen P, Ebbesen F, et al. Nasal continuous positive airway pressure and early surfactant therapy for respiratory distress syndrome in newborns of less than 30 weeks' gestation. Pediatrics. 1999;103(2):E24.

21. Berggren E, Liljedahl M, Winbladh B, et al. Pilot study of nebulized surfactant therapy for neonatal respiratory distress syndrome. Acta Paediatr. 2000;89(4):460-464.

22. Finer NN, Higgins R, Kattwinkel J, Martin RJ. Summary proceedings from the apnea-of-prematurity group. Pediatrics. 2006;117(3 Pt 2): S47-S51.

23. Arroe M, Pedersen-Bjergaard L, Albertsen P, et al. Inhalation of aerosolized surfactant (Exosurf $(\mathrm{R})$ ) to neonates treated with nasal continuous positive airway pressure. Prenat Neonatal Med. 1998;3: 346-352.

24. Shah S. Exogenous surfactant: intubated present, nebulized future? World J Pediatr. 2011;7(1):11-15.

25. Saslow JG, Aghai ZH, Nakhla TA, et al. Work of breathing using high-flow nasal cannula in preterm infants. J Perinatol. 2006;26(8):476-480.

26. Wilkinson D, Andersen C, O’Donnell CPF, De Paoli AG. High flow nasal cannula for respiratory support in preterm infants. Cochrane Database Syst Rev. 2011;5:CD006405.

27. Nair, Karna. Comparison of the effects of Vapotherm and nasal CPAP in respiratory distress. E-PAS. 2005;57:2054.

28. Campbell DM, Shah PS, Shah V, et al. Nasal continuous positive airway pressure from high flow cannula versus Infant Flow for preterm infants. J Perinatol. 2006;26(9):546-549.
29. Bhandari V, Gavino RG, Nedrelow JH, et al. A randomized controlled trial of synchronized nasal intermittent positive pressure ventilation in RDS. J Perinatol. 2007;27(11):697-703.

30. Meneses J, Bhandari V, Alves JG, Herrmann D. Noninvasive ventilation for respiratory distress syndrome: a randomized controlled trial. Pediatrics. 2011;127(2):300-307.

31. Kugelman A, Feferkorn I, Riskin A, Chistyakov I, Kaufman B, Bader D. Nasal intermittent mandatory ventilation versus nasal continuous positive airway pressure for respiratory distress syndrome: a randomized, controlled, prospective study. J Pediatr. 2007;150: 521-526.

32. Bisceglia, Belcastro, Poerio, et al. A comparison of nasal intermittent versus continuous positive pressure delivery for the treatment of moderate respiratory syndrome in preterm infants. Minerva Pediatr. 2007;59(2):91-95.

33. Sai Sunil Kishore M, Dutta S, Kumar P. Early nasal intermittent positive pressure ventilation versus continuous positive airway pressure for respiratory distress syndrome. Acta Paediatr. 2009;98(9):1412-1415.

34. Ramanathan R, Sekar KC, Rasmussen M, Bhatia J, Soll RF. Nasal intermittent positive pressure ventilation (NIPPV) versus synchronized intermittent mandatory ventilation (SIMV) after surfactant treatment for respiratory distress syndrome (RDS) in preterm infants $<30$ weeks gestation: multicenter, randomized, clinical trial. EPAS. 2009;3212: 3216.

35. McMaster University; Canadian Institutes of Health Research. Nasal intermittent positive pressure ventilation in premature infants (NIPPV). In: ClinicalTrials.gov [internet]. Bethesda, MD: National Library of Medicine (US). February 7, 2007 [last updated on August 4, 2011]. Available from: http://clinicaltrials.gov/ct2/show/NCT00433212?ter $\mathrm{m}=$ nct00433212\&rank=1. NLM identifier: NCT00433212.

36. Laughon M, Bose C. Prophylactic nasal intermittent positive pressure ventilation (NIPPV) versus prophylactic nasal continuous positive airway pressure (NCPAP) for preterm infants - Review protocol. Cochrane Lib. 2009:1. doi: 10.1002/14651858.CD005384.

37. Clarke M. Standardising outcomes in paediatric clinical trials. PLoS Med. 2008;5(4):e102.

38. Sinha IP, Smyth RL, Williamson PR. Using the Delphi technique to determine which outcomes to measure in clinical trials: recommendations for the future based on a systematic review of existing studies. PLoS Med. 2011;8(1):e1000393.

39. Sinha I, Jones L, Smyth RL, Williamson PR. A systematic review of studies that aim to determine which outcomes to measure in clinical trials in children. PLoS Med. 2008;5(4):e96.

40. Engle, William A. Surfactant-replacement therapy for respiratory distress in the preterm and term neonate. Pediatrics. 2008;121(2):419-432.

41. Fuchs H, Lindner W, Leiprecht A, Mendler MR, Hummler HD. Predictors of early nasal CPAP failure and effects of various intubation criteria on the rate of mechanical ventilation in preterm infants of $<29$ weeks gestational age. Arch Dis Child Fetal Neonatal Ed. 2011;96(5): F343-F347.

42. Ammari A, Suri M, Milisavljevic V, et al. Variables associated with the early failure of nasal CPAP in very low birth weight infants. $J$ Pediatr. 2005;147(3):341-347.

43. Navalesi P, Costa R. New modes of mechanical ventilation: proportional assist ventilation, neurally adjusted ventilatory assist, and fractal ventilation. Curr Opinin Crit Care. 2003;9(1):51-58.
Research and Reports in Neonatology

\section{Publish your work in this journal}

Research and Reports in Neonatology is an international, peer-reviewed, open access journal publishing original research, reports, editorials, reviews and commentaries on neonatal health. The manuscript management system is completely online and includes a very quick and fair
Dovepress

peer-review system. Visit http://www.dovepress.com/testimonials.php to read real quotes from published authors. 